\title{
LOW TEMPERATURE PROPERTIES OF FUEL MIXTURES OF KEROSENE AND FAME TYPE USED TO SUPPLY TURBINE ENGINES IN MARINE AND OTHER NON-AERONAUTICAL APPLICATIONS
}

\author{
Wojciech Dzięgielewski, Ph. D \\ Bartosz Gawron, Ph. D \\ Andrzej Kulczycki, Assoc. Prof. \\ Air Force Institute of Technology
}

\begin{abstract}
A worldwide trend to popularise gradually increasing use of biofuels in various applications was a motivation for gaining interest in FAME as a commonly available biocomponent to fuels combusted in turbine engines. These engines are mainly used in aeronautics, but many of them are also used in other, non-aeronautical areas, including marine navigation. Specific conditions in which fuels are combusted in turbine engines used in these applications are the reason why fuel mixtures of kerosene and FAME type should reveal relevant low temperature characteristics. The article presents results of tests of low temperature properties of mixtures of the jet fuel Jet A-1 and methyl esters of higher fatty acids (FAME). The prepared mixtures contained different contents of FAME. The obtained results present changes of: viscosity, cloud point, pour point, crystallising point, and cold filter plugging point, depending on the percentage by volume of FAME. They also prove that the course of changes of low temperature properties of these mixtures is affected by chemical structure of the biocomponent.
\end{abstract}

Keywords: jet fuel, biocomponents, marine turbine engine, low temperature properties

\section{Introduction}

The idea of introducing biocomponents to liquid fuels combusted in engines in all transport sectors has been popularised since the turn of the twenty-first century. Possible applications of biofuels in land and sea transport, and in aviation were indicated. The idea of using biocomponents in fuels also expanded to the area of fuel supply for various types of engines, including combustion engines of both piston and turbine type $[1-4]$.

In years 2007-2009, a research programme was conducted in the Air Force Institute of Technology which was oriented on examining the applicability of the biocomponent of FAME type - methyl esters of higher fatty acids, in aircraft turbine engines. The performed tests [5] have revealed limited applicability of the $1^{\text {st }}$ generation biocomponent - FAME as the component of fuels used in aircraft applications. It turned out that the most severe limitation is imposed by the effect of esters on fuel properties associated with water separation, which in case of aeronautical applications can constitute a threat to the safety of operation. Even small additive of FAME leads to remarkable changes in the fuel surface tension, thus disturbing the mechanism of water separation from fuel in coalescer filters. As a result, the water cannot be removed and the risk of trouble in low temperature operation increases. However, the above problem does not disqualify the FAME type biocomponent as the component of fuels used to supply turbine engines in other transport sectors. [6,7].

Due to their numerous structural and operating advantages, turbine engines are being more and more commonly used in other areas of engineering than aviation. In particular, they find wide application as watercraft propulsion units. High costs of new engine designs are a reason why marine turbine engines are frequently derived from tried and tested aircraft structures of propeller and helicopter types. As far as the supply system is concerned, their modernisation consists in adapting these engines to combust diesel fuels and work in sea environment [8]. Turbine engines can also be used as propulsion for power generating sets, or stationary peak power plants.

In real operation the dependence of fuel properties on temperature is of high importance. When the temperature decreases, essential rheological properties of the operating liquid change. Loss of fluidity of the fuel can lead to filter plugging or the increase of pumping resistance loss, which can make pumping the fuel from tanks to the engine impossible. 
Low temperature properties are extremely important when FAME is added to the fuel, as a main disadvantage of this biocomponent is that is reveals remarkably worse low temperature properties than oil products.

The paper presents results of tests of low temperature properties of mixtures of the jet fuel Jet A-1 with FAME in different proportions. Discussed are changes of essential low temperature parameters of the tested mixtures depending on the percentage by volume of FAME in the fuel, and on differences in chemical structure of the biocomponent itself. The obtained results reveal that low temperature properties of Jet A-1/FAME mixtures are subject to changes depending on concentration of the biocomponent. These changes are not monotonous in nature and strongly depend on the chemical structure of FAME.

\section{Materials and research methodology}

\section{Fuel mixtures}

Samples of Jet A-1 fuel for aircraft turbine engines which were used in the tests came from two different sources. Moreover, the used methyl esters of higher fatty acids also came from different agro refineries. One sample was prepared from a mixture of different esters.

Initially, test were performed for individual basic components, i.e. the jet fuel Jet A-1 and FAME which were then used for preparing the mixtures. All samples met basic standard requirements, but differences between properties of particular FAME samples suggested different chemical composition.

Basic components which were used to prepare mixtures were:

1. JetA-1 (source 1) and FAME (agro refinery) -symbol M1.

2. JetA-1 (source 1) and FAME (mixture) - symbol M2.

3. JetA-1 (source 2) and FAME (agro refinery) - symbol M3.

4. JetA-1 (source 2) and FAME (mixture) - symbol M4.

Each mixture contained different percentages of methyl esters of higher fatty acids - 0,5\%, $1 \%, 2 \%, 3 \%, 4 \%, 5 \%, 6 \%$, $7 \%, 8 \%, 9 \%, 10 \%, 11 \%, 12 \%, 13 \%, 14 \%, 15 \%, 16 \%, 17 \%, 18 \%$, $19 \%$ and $20 \%(\mathrm{~V} / \mathrm{V})$.

\section{Research methodology}

Low temperature properties of the mixtures were tested in the Division of Propellants and Greases, Air Force Institute of Technology, based on standardised and accredited test methods.

Basic low temperature properties of fuels include: kinematic viscosity, crystallising point, cloud point - CP, pour point - PP, and cold filter plugging point - CFPP. A detailed description of the procedure used to assess each of these properties is given in the test method (Table 1).
Tab. 1. Test methods used to examine low temperature properties of kerosene fuel

\begin{tabular}{|l|c|}
\hline \multicolumn{1}{|c|}{ Name of property } & Test method \\
\hline Kinematic viscosity at temperature $-20^{\circ} \mathrm{C}, 0^{\circ} \mathrm{C},+20^{\circ} \mathrm{C}$ & PN-EN ISO 3104 \\
\hline Crystallising point & ASTM D 2386 \\
\hline Cloud point & ASTM D 2500 \\
\hline Pour point & ASTM D 97 \\
\hline Cold filter plugging point & PN-EN-116 \\
\hline
\end{tabular}

\section{Results of tests and their discussion}

The effect of FAME content on kinematic viscosity of the selected mixtures M2 and M4 at the temperatures of $-20{ }^{\circ} \mathrm{C}, 0{ }^{\circ} \mathrm{C}$, and $+20^{\circ} \mathrm{C}$ is illustrated in Figs. 1 and 2 . For two remaining mixtures the qualitative course of kinematic viscosity changes at the above temperatures was similar.

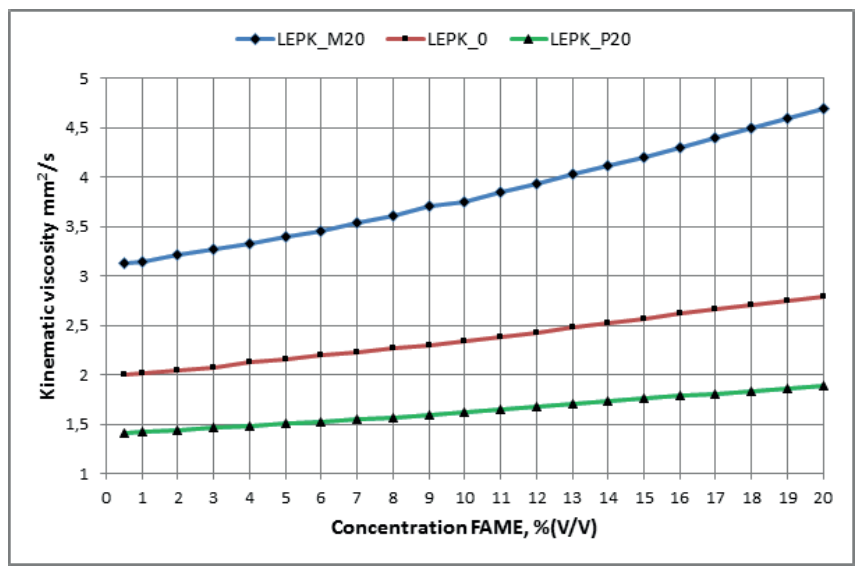

Fig. 1. Viscosity changes of mixture M2 depending on FAME concentration and test temperature (LEPK_M20 - kinematic viscosity at temp. of $-20^{\circ} \mathrm{C}$ $L E P K \_0$ - kinematic viscosity at temp. of $0^{\circ} \mathrm{C}, L E P K \_P 20$ - kinematic viscosity at temp. of $+20^{\circ} \mathrm{C}$ )

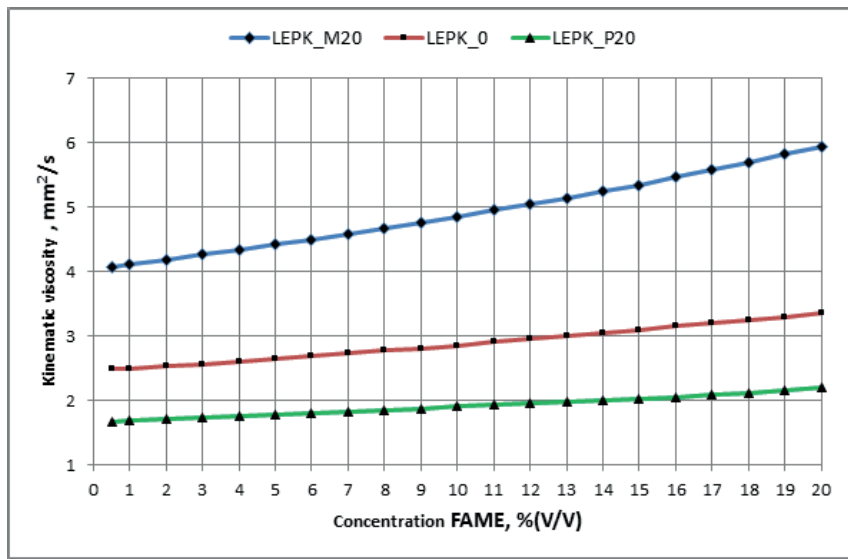

Fig.2. Viscosity changes of mixture M4 depending on FAME concentration and test temperature (LEPK_M20 - kinematic viscosity at temp. of $-20^{\circ} \mathrm{C}$, LEPK_0 - kinematic viscosity at temp. of $0{ }^{\circ} \mathrm{C}, L E P K \_P 20$ - kinematic viscosity at temp. of $+20^{\circ} \mathrm{C}$ ) 
For all types of mixtures, kinematic viscosity values at temperatures of $-20^{\circ} \mathrm{C}, 0{ }^{\circ} \mathrm{C}$, and $+20^{\circ} \mathrm{C}$ reveal an increasing trend with the increase of the content of esters. Up to $20 \%$ (V/V) of FAME content, the values of this parameter are within the limits of the standards $[9,10]$ for jet fuel (max. $8,0 \mathrm{~mm}^{2} / \mathrm{s}$ at temp. of $-20^{\circ} \mathrm{C}$ ). The highest kinematic viscosity, equal to $5,937 \mathrm{~mm}^{2} / \mathrm{s}$ at temp. of $-20{ }^{\circ} \mathrm{C}$, was obtained for mixture M4 and FAME content equal to $20 \%$.

Below given are the results and analysis of the effect of FAME content on typical low temperature properties of fuel mixtures.

Taking into account physical properties of the biocomponent (Table 2) - especially worsening of these properties in low temperatures (methyl esters of fatty acids produced from rapeseed oil - RME (rapeseed methyl ester) - lose fluidity at temperatures below $-18{ }^{\circ} \mathrm{C}$, while for esters produced from other vegetable or animal fats this temperature is even higher), an expected result was remarkable worsening of low temperature properties of the prepared mixtures.

Tab.2. Low temperature properties of basic fuels, based on literature data [11] and in-house tests

\begin{tabular}{|c|c|c|c|c|}
\hline & \multicolumn{2}{|c|}{ RME } & \multicolumn{2}{c|}{ JetA-1 } \\
\hline Parameter & $\begin{array}{c}\text { Results acc. to } \\
{[11]}\end{array}$ & $\begin{array}{c}\text { In-house } \\
\text { test }\end{array}$ & $\begin{array}{c}\text { Results acc. to } \\
{[11]}\end{array}$ & $\begin{array}{c}\text { In-house } \\
\text { test }\end{array}$ \\
\hline Pour point (PP), ${ }^{\circ} \mathrm{C}$ & -12 & - & -51 & - \\
\hline Cloud point(CP), ${ }^{\circ} \mathrm{C}$ & -4.1 & - & -26.0 & - \\
\hline Crystallising point, ${ }^{\circ} \mathrm{C}$ & - & - & - & -55 \\
\hline $\begin{array}{c}\text { Cold filter plugging } \\
\text { point(CFPP), }{ }^{\circ} \mathrm{C}\end{array}$ & -15 & -15 & -46 & -49 \\
\hline
\end{tabular}

Results of pour point (PP) tests for mixtures containing different contents of FAME are shown in Fig. 3.

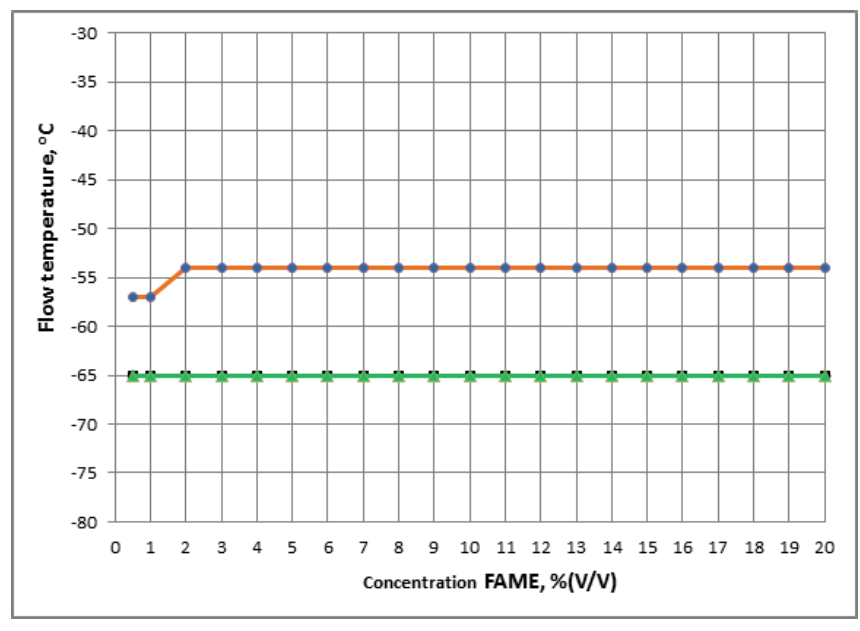

Fig. 3. Pour point changes for mixtures of jet fuel Jet A-1 with different FAME contents

The obtained results differ from those expected, as for all tested samples of mixture the pour point does not change with the increasing FAME content in the jet fuel JetA-1, while the results presented in Ref. [11] suggest that the increasing content of FAME in the mixture should increase the pour point of this mixture. The pour point for the pure jet fuel is approximately equal to $-51^{\circ} \mathrm{C}$, while the results obtained in the tests suggest that the pour points of the prepared mixtures are lower.

The course of changes of the cloud point (Fig. 4) for all mixtures and the FAME content from 0 to $20 \%$ (V/V) also differs from that shown in Ref. [11]. Some similarities can only be observed for the FAME content above $10 \%$, when for the increased content of this biocomponent in the tested mixtures a regular cloud point increase is observed. The highest cloud point value, equal to $-27{ }^{\circ} \mathrm{C}$, occurs for all tested mixtures when the FAME content in the fuel is $20 \%(\mathrm{~V} / \mathrm{V})$.

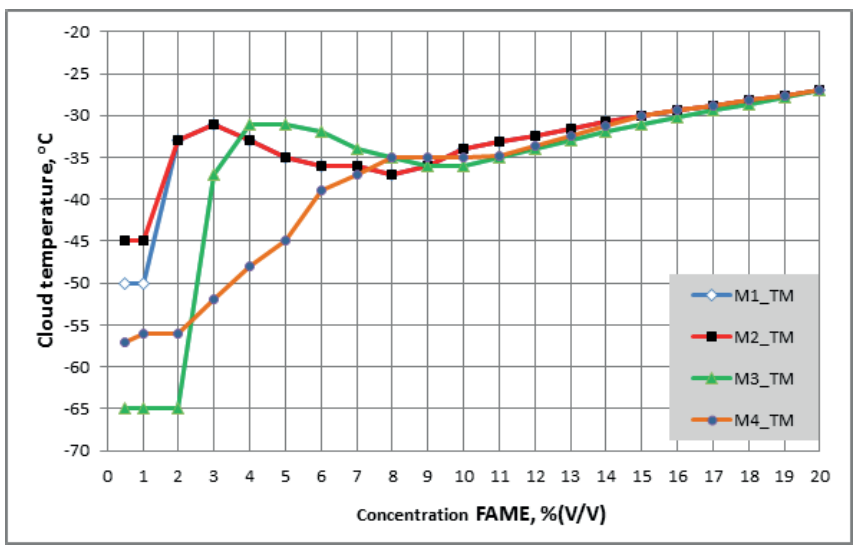

Fig. 4. Cloud point changes for mixtures of jet fuel JetA-1 with different FAME contents.

The highest irregularities are observed within the FAME content range of up to about $10 \%$. Here, a general trend of cloud point changes for all three mixtures is similar, i.e. for low FAME content the cloud point increase rapidly, and then decreases with the increasing FAME content. The obtained results are in opposition to commonly accepted opinions that the FAME content only leads to worsening of low temperature properties of the fuel mixture. The presented tests reveal that a certain FAME content can result in decreasing of the cloud point. This effect can be explained by the existence of different mechanisms of cooperation of fuel components at their different concentrations in the mixture. Only for the mixture M4 a continuous increasing trend of this parameter is observed for the increasing FAME content. Different patterns of particular curves clearly indicate the effect of differences in the chemical composition of FAME (esters in particular mixtures came from different deliverers) on the cloud point of the examined mixtures.

The course of changes of the crystallising point in relation to FAME content is very irregular for the examined mixtures (Fig. 5), with no clear trend observed for this parameter.

Up to about $10 \%(\mathrm{~V} / \mathrm{V})$ of FAME content, the crystallising point for all mixtures changes intensively and irregularly (its values increase and decrease), while above $10 \%(\mathrm{~V} / \mathrm{V})$ of FAME content in the fuel, curve patterns become more regular. In cases of mixtures M1 and M2 the crystallising point values decrease with the increasing FAME content. For mixture M4 its values initially increase and then decrease, 
and for mixture M3 the crystallising point values slightly increase. All this means that also for the crystallising point, certain FAME content in the fuel can decrease its value i.e. improve low temperature properties of the mixture. Like for previous parameters, this conclusion is also in some opposition to common opinions. It is noteworthy that the tests brought numerous crystallising point values for Jet A-1/ FAME mixtures which were lower than $-55^{\circ} \mathrm{C}$, which is the crystallising point for pure jet fuel (Table 2).

Other data than that published in the literature [11] was also obtained in cold filter plugging point (CFPP) tests. These results are shown in Fig. 6.

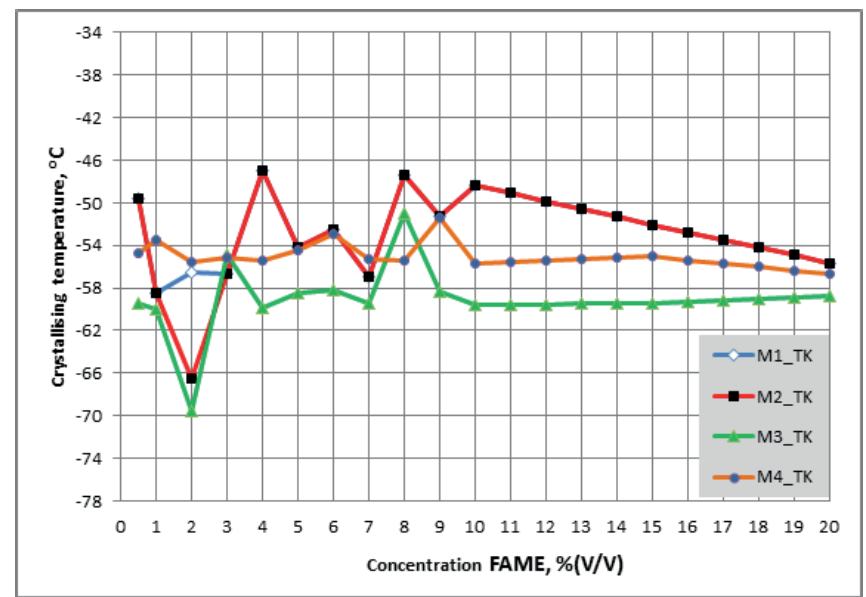

Fig. 5. Crystallising point changes for mixtures of jet fuel JetA-1 with different FAME contents.

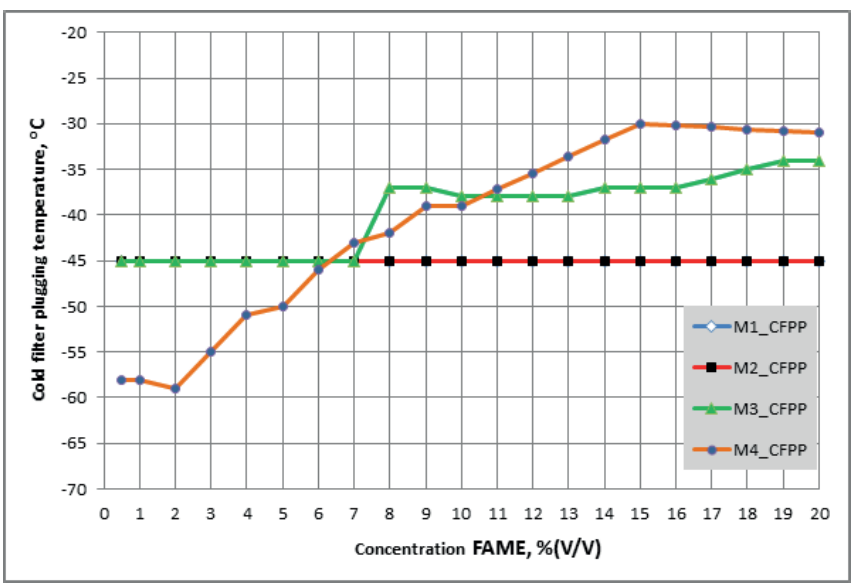

Fig. 6. Cold filter plugging point changes for mixtures of jet fuel JetA-1 with different FAME contents.

The increasing FAME content in the fuel does not affect this parameter in case of mixtures $\mathrm{M} 1$ and M2, as well as for mixture M3 with FAME content of up to 7\% (V/V). For the latter mixture, within the FAME content above $7 \%(\mathrm{~V} / \mathrm{V})$ the values of this parameter increase with the increasing FAME content. Only in case of mixture M4 almost regular relation between CFPP and FAME content was observed: the increasing FAME content in the mixture led to the increase of CFPP. The above results illustrate high importance of chemical composition of the prepared mixtures, which decides about the existence of certain mechanisms of cooperation between particular components and thus affects the cold filter plugging point value. Also in this case, a statement that the presence of FAME definitely worsens low temperature properties concerning CFPP is not true.

\section{Summary and concluding remarks}

1. The performed tests of low temperature properties of Jet A-1/FAME mixtures have indicated some potential for the use of this biocomponent to supply turbine engines in marine and other non-aeronautical applications. Pure FAME reveals poor low temperature properties, which limits its applicability. However, low temperature properties of oil fuel mixtures with this biocomponent allow them to be used within temperatures down to about $-25{ }^{\circ} \mathrm{C}$, as the highest value of the cold filter plugging point recorded during the tests was approximately equal to $-30^{\circ} \mathrm{C}$, and the highest cloud point value was $-27^{\circ} \mathrm{C}$.

2. In case of turbine engines used in marine engineering, there is no threat for the fuel to be exposed to such low values. Consequently, introducing FAME to the fuel will not endanger engine operation in this area.

3. Low temperature properties of mixtures of the jet fuel Jet A-1 and FAME depend on FAME content by volume in the fuel and its chemical composition. Differences in chemical composition of FAME which are significant to low temperature properties result from the quality and type of raw materials used by different producers and the applied transesterification technology.

4. Low temperature parameters of Jet A-1/FAME fuels do not change in proportion to the content of this biocomponent in the fuel. Within some ranges the increased FAME content in the fuel worsens its low temperature properties, although some improvement is also observed for low FAME contents.

5. The above conclusions clearly indicate the existence of some cooperation between FAME components and those of the mineral fuel Jet A-1. The mechanism of this cooperation is strongly affected by chemical composition of FAME. An attempt to recognise the course and reasons of this mechanism will be the subject of further research.

\section{References}

1. Dzięgielewski W., Karp G., Factors and Threats Regarding Sustainability criteria Meeting In Chain of Fuels Biocomponents Production in Poland; Polish Journal of Environmental Studies, vol. 22, No. 6A (2013), ss. 7 - 11.

2. Kaźmierczak U., Kulczycki A., The Possibilities of 
Biocomponents to Meet the Sustainability Criteria Turing years 2017 and 2018 in the Extend of GHG Emission by Modification of their Production Technology and using RES in Energy Infrastructure, Polish Journal of Environmental Studies, vol. 22, No. 6A (2013), ss. 18 - 21.

3. Dzięgielewski W., Gawron B., Kaźmierczak U., Kulczycki A., Butanol / biobutanol as a Component of an Aviation and Diesel Fuels; Journal of Kones Powertrain and Transport, vol. 21, No. 2 2014, ss. 69 - 76

4. Wright M., Biomass to Alcohol to Jet/Diesel; Research Department Chemistry Division Naval Air Warfare Center Weapons Division, China Lake, CA 93555

5. Dzięgielewski W., Biofuel for aircraft turbine engines (in Polish), Final report from the research and development project "Biofuel for aircraft turbine engines", ITWL 2010.

6. Dzięgielewski W., Gawron B., Testing applicability of 1st generation biocomponents for fuels used in aircraft turbine engines (in Polish), Prace Naukowe Instytutu Technicznego Wojsk Lotniczych, nr 302012.

7. Dzięgielewski W., Kulczycki A., Aircraft biofuels based on biohydrocarbons and other biocomponents (in Polish), Journal of KONBIN, nr 1(17) 2011.

8. Niedziałek B., Balicki W., Gryglewski W., The applicability of GTD-350 engine for non-aeronautical purposes (in Polish), Conference „Silwoj”, Jurata 2003.

9. Defence Standard NO-91-A258-4 „Propellants and greases. Fuel for aircraft turbine engines (in Polish). Paliwokod NATO F-35".

10. Aviation Fuel Quality Requirements For Jointly Operated Systems (AFQRJOS) Issue 26 - May 2012.

11. Baczewski K., Szczawiński S., Investigation properties of rapeseed oil methyl esters/aviation turbine fuel Jet A-1 blends, Journal of KONES Powertrain and Transport, Vol. 18, No. 12011.

\section{CONTACT WITH AUTHOR}

Wojciech Dzięgielewski

Bartosz Gawron

Andrzej Kulczycki

Air Force Institute of Technology

6 Księcia Bolesława St.

01-494 Warszawa

POLAND 